\section{Summer School}

The International Summer School on Plasma Chemistry to be held prior to the Symposium, 29-31 July 1999, will consist of courses providing an introduction to the fundamentals of plasma chemistry and the applications of plasma processing. Two courses will be offered simultaneously, one on low-pressure nonequilibrium plasmas and the other on thermal plasmas. These courses are intended for students, scientists, engineers, and managers who want an introduction to, or overview of, the subject or better appreciation of the topics presented at the Symposium. There will be a separate registration fee for the Summer School.

\section{Workshop}

The workshop on Industrial Applications of Plasma Processing will be held following the Symposium, 67 August 1999.

The workshop will focus on recent industrial applications, developments, and concerns in thermal and low-pressure plasma processing. The workshop will enable the exchange of ideas between researchers, manufacturers, and end users. There will be a separate registration fee for the workshop

\section{Exhibition}

A professional exhibition of equipment for plasma processing, diagnostics, instrumentation, etc. will be held during the Symposium. Firms interested in showing their products should contact the Local Organising Committee.

\section{Venue}

The Symposium Exhibition and Workshop will be held in the Congress Centre of the Prague Hilton Hotel situated just at the boundary of the old town. Accommodations will be available in the Hilton Hotel, at several hotels in the vicinity, and in student hostels.

\section{6th International Conference on Methods and Appplications of Fluorescence Spectroscopy (MAFS6), 12-15 September 1999, Paris, France}

\section{General Information}

The 6th International Conference on Methods and Applications of Fluorescence Spectroscopy will be held in Paris, France, 12-15 September 1999. This Conference is organized in alternate years. The preceding conferences took place in Graz, Austria (1989 and 1991), Prague, Czech Republic (1993), Cambridge,
England (1995) and Berlin, Germany (1997).

This Conference aims at bringing together researchers working in various fields who employ fluorescence as a tool of investigation for both fundamental and applied purposes. Applications in chemistry, physics, biology, and medicine are covered.

The Conference will start on Sunday afternoon and end on Wednesday afternoon. The scientific program includes about 20 lectures and an extensive poster session, together with a commercial exhibition.

A guided visit of either the Louvre or Orsay Museums and a dinner during a boat cruise on the river Seine are planned in the social program.

\section{List of Topics}

\section{Methods}

Fluorescent probes

Time-resolved techniques

Energy transfer

Fluorescence depolarization

Fluorescence microscopy

Multiphoton excitation

Single molecule detection

Fluorescence correlation spectroscopy

Near-field fluorescence spectroscopy

Applications

Molecular and cellular biology

Polymers

Organized media

Supramolecular systems

Fluorescent sensors

Clinical analysis

Diagnostics

Environment

Imaging (biology, medicine)

\section{Inquiries about MAFS6}

Prof. Bernard Valeur, MAFS6, Conservatoire National des Arts et Métiers, 292, rue Saint-Martin, F-75141 Paris Cedex 03, France; Tel: +33 31402723 89; Fax: +31 402723 62; E-mail: mafs6@cnam.fr; web site: http://www.lbpa.ens-cachan.fr/photobm/mafs6.

\section{6th International Symposium on Hyphenated Techniques in Chromatography (HTC-6), 9-11 February 2000, The Saint John's Conference Centre, Bruges, Belgium}

This international symposium will be supported by tutorials. The scientific program will comprise both oral and poster presentations. The deadline for submitting abstracts is 30 June 1999. Abstracts for last-minute poster presentations will be accepted up 
to 15 December 1999.

Contact: HTC-6 Congress Secretariat, Ordibo bvba, Lucas Henninckstraat 20, B-2610 Wilrijk (Antwerp), Belgium; Tel.: +32 (3) 561 2831; Fax: +32 (3) 827 8439; e-mail: smitsr@ pophost.eunet.be; home page for updated program: http://www.ordibo.be/htc.

\section{World Congress of Food Science \& Technology, 3-8 October 1999, Sydney, Australia}

For further information contact: IUFoST Congress 10, P.O. Box 1493, North Sydney, NSW 2059, Sydney, Australia; Tel: +61 2 9959 4499; Fax: +61 29954 4327; E-mail: iufost10@alfst.asn.au; website: http:// alfst.asn.au

\section{Plutonium Futures-The Science, 10-14 July 2000, Santa Fe, New Mexico, USA}

This conference, the second in a series, is designed to be an interdisciplinary forum to present and discuss current research on physical and chemical properties of plutonium and other actinide elements. This forum will have international participation to discuss current and emerging science (chemistry, physics, materials science, nuclear science, and actinides in the environment) of actinides relevant to enhancing global nuclear security. Contact K. C. Kim, K. K. S. Pillay; Tel: +1 505667 7753; Fax: +1 505667 7966; E-mail: puconf2000@lanl.gov, http://www.lanl.gov/Pu2000. html.

\section{5th World Congress of Theoretically Oriented Chemists, (WATOC'99), 1-6 August 1999, Imperial College, London, UK}

For further information see the WATOC'99 web site: http://www.chemsoc.org/watoc'99/.

\section{International Symposium on Macrocyclic Chemistry (ISMC'99), 18-23 July 1999, Barcelona, Spain}

For further information see the ISMC'99 web site: http://www1.uji.es/ismc.

New Books and Publications

\section{New Publications from the World Health Organization}

\section{Concise International Chemical Assessment Documents (CICADs)}

Concise International Chemical Assessment Documents (CICADs) are the latest in a family of publications from the International Program on Chemical Safety (IPCS), a cooperative program of the World Health Organization (WHO), the International Labour Organisation (ILO), and the United Nations Environment Program (UNEP). CICADs join the Environmental Health Criteria documents (EHCs) as authoritative documents on the risk assessment of chemicals.

CICADs are concise documents that provide summaries of the relevant scientific information concerning the potential effects of chemicals upon human health and/or the environment. They are based on selected national or regional evaluation documents or on existing EHCs. Before acceptance for publication as CICADs by IPCS, these documents undergo extensive peer review by internationally selected experts to ensure their completeness, accuracy in the way in which the original data are represented, and the validity of the conclusions drawn.

The primary objective of CICADs is characterization of hazard and dose-response from exposure to a chemical. CICADs are not a summary of all available data on a particular chemical; rather, they include only that information considered critical for characterization of the risk posed by the chemical. The critical studies are, however, presented in sufficient detail to support the conclusions drawn. For additional information, the reader should consult the identified source documents upon which the CICAD has been based.

Risks to human health and the environment will vary considerably depending upon the type and extent of exposure. Responsible authorities are strongly encouraged to characterize risk on the basis of locally measured or predicted exposure scenarios. To assist the reader, examples of exposure estimation and risk characterization are provided in CICADs, whenever possible. These examples cannot be considered as representing all possible exposure situations, but are provided as guidance only. The reader is referred to EHC 170 for advice on the derivation of health-based guidance values. 